\title{
Assessing the Vulnerability of Kota Kinabalu Buildings
}

\author{
Noor Sheena Herayani Harith ${ }^{1,2,}$, Viliana Jainih ${ }^{1}$, Mohd Azizul Ladin ${ }^{1}$, Mohd Irwan Adiyanto ${ }^{3}$ \\ ${ }^{1}$ Faculty of Engineering, Universiti Malaysia Sabah (UMS), Jalan UMS, 88400 Kota Kinabalu, Sabah, Malaysia \\ ${ }^{2}$ Natural Disaster Research Center, Faculty of Science \& Natural Resources, Universiti Malaysia Sabah (UMS), 88400 Kota Kinabalu, \\ Sabah, Malaysia \\ ${ }^{3}$ Department of Civil Engineering, College of Engineering, Universiti Malaysia Pahang (UMP), Gambang, Malaysia
}

Received February 28, 2021; Revised July 30, 2021; Accepted August 9, 2021

\section{Cite This Paper in the following Citation Styles}

(a): [1] Noor Sheena Herayani Harith, Viliana Jainih, Mohd Azizul Ladin, Mohd Irwan Adiyanto , "Assessing the Vulnerability of Kota Kinabalu Buildings," Civil Engineering and Architecture, Vol. 9, No. 5A, pp. 68 - 77, 2021. DOI: 10.13189/cea.2021.091308.

(b): Noor Sheena Herayani Harith, Viliana Jainih, Mohd Azizul Ladin, Mohd Irwan Adiyanto (2021). Assessing the Vulnerability of Kota Kinabalu Buildings. Civil Engineering and Architecture, 9(5A), 68 - 77. DOI: 10.13189/cea.2021.091308.

Copyright $\odot 2021$ by authors, all rights reserved. Authors agree that this article remains permanently open access under the terms of the Creative Commons Attribution License 4.0 International License

\begin{abstract}
A gradual increase in moderate and low seismic activity has occurred in Sabah over the course of several years due to the presence of certain moderately active fault lines in the region. Around 300 moderate earthquakes with magnitudes ranging from $\mathrm{M}_{W} 4.0$ to 7.0 have occurred in the last 120 years. The majority of existing buildings in Sabah are wind and gravity loaded. This study proposes a preliminary seismic vulnerability assessment methodology based on empirical and analytical vulnerability method for 250 existing buildings in Kota Kinabalu city. The empirical vulnerability assessment focuses on building evaluation utilizing a standard Rapid Visual Screening (RVS) method and the FEMA 154 guidebook's moderate seismicity assessment form. A field survey was conducted on the buildings ranging in height from low-rise to high-rise. As a result, when subjected to moderate-intensity earthquakes, $60 \%$ of the buildings are classed as susceptible and vulnerable to seismic hazard. The current study included the use of nonlinear static analysis to seven different building cases for further investigation. The findings of the analysis demonstrate that the majority of the buildings respond linearly elastical when subjected to peak ground acceleration (PGA) at $0.17 \mathrm{~g}$, which indicate that, buildings without seismic design accumulate damage early when subjected to moderate earthquake loadings.
\end{abstract}

Keywords Rapid Visual Screening, Building Vulnerability, Kota Kinabalu

\section{Introduction}

Active seafloor in Sulawesi and the Philippines influences earthquake activity in Sabah, which is located in the South China Sea Basin. Local earthquakes have an impact on the region as well. An earthquake occurs when there is a sudden and unexpected shift in the ground. The stress along faults is released, and this results in the emission of seismic energy, causing the ground to shake. Malaysia is situated on the Sunda tectonic plate, which covers a large portion of Southeast Asia [1]. Malaysia was once thought to be relatively stable continent. However, the 6.0 magnitude earthquake that struct Ranau, Sabah in June 2015 has alarmed both local and international researchers and institutional organizations, prompting them to investigate the area's seismic vulnerability and local ground movements. The earthquake was the most powerful recorded in Malaysia in the previous 120 years, dating back to 1900. Seismic activity in Sabah dates all the way back to 1900 [2,3], and is triggered by shallow crustal faults. 


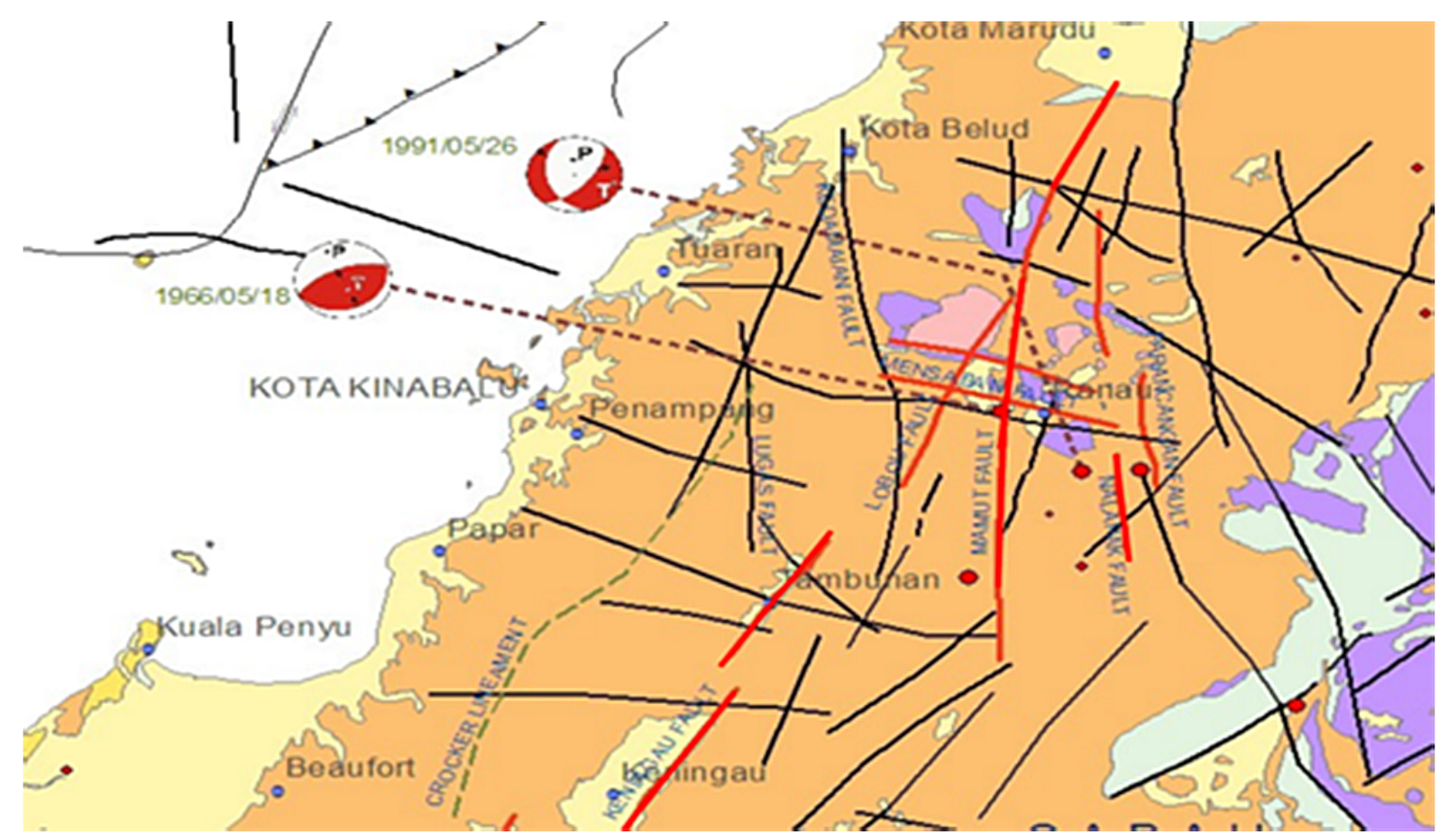

Figure 1. Active fault lines in the North-Western Sabah [4]

As a result of this occurrence, Malaysia has become one of the continents that are no longer safe from catastrophic plate tectonic events such as earthquakes. According to past earthquake statistic records, Sabah is more susceptible to earthquake activity than twelve Malaysian states and is classed as a seismically active zone. Active fault movement can be observed along the Mensaban fault and Lobou-Lobou fault zones, which are particularly prominent in North-Western Sabah. These two fault zones, which are in the vicinity of Kundasang, Ranau, are portrayed in Figure 1 as being in close proximity to one another. Both faults are designated as active by the Malaysian Meteorological Department (METMalaysia) based on previous local ground motion recordings.

\section{Literature Review}

The earthquake activity in Sabah ranges from low to moderate [5-7]. Sabah is prone to earthquake due to its location near the south-eastern Eurasian Plate, which is bounded by the Pacific Plate and the Philippine Plate. Ground motions are caused by interactions between the main tectonic plates and their respective active fault lines. Local-originated earthquakes of magnitudes up to MW 6.0 had occurred in Sabah. Large scale magnitude centred along the Straits of Macassar and the Southern Philippines, the Celebes and Sulu Sea have additionally impacted Sabah over the years. Ground shaking from neighbouring countries and local earthquakes can cause fatalities and significant property damage; yet, the vast majority of existing structures were constructed without regard for seismic risk when they were constructed. In Malaysia, tremors are becoming more frequent because of rising earthquake activity in the region, requiring the implementation of seismic design. This region's seismicity is significantly lower than that of other moderate seismicity regions; however the threat of earthquakes should not be overlooked.

According to one article by Inus [8], Sabah would experience a greater earthquake in the future, similar to Ranau case. Seismic risk assessment is an essential technique for managing the growing threat of high seismic activity on existing buildings. Previous research indicates that the vulnerability of buildings to ground motion is a well-known basic feature in any seismic risk model. Various approaches perform seismic vulnerability, according to Lang [9] and Calvi et al. [10]. Either a quantitative or qualitative approach might be used to complete the task. The quantitative evaluation is based on observable vulnerability, expert opinion, or score assignments, whereas the qualitative evaluation is based on empirical methodologies or an analytical procedure.

The score assignment approach, as described by Ghafar et al. [11], Mansor et al. [12], and Mohamad et al. [13], is a regularly used method for seismic vulnerability in Sabah. Rapid visual evaluation, such as the FEMA 154 [14] technique, is the easiest method. The empirical method's output includes the key components of the building's capacity and seismic demand. Calvi et al. [10] are referred 
to for a high quality, dependable, and extensive survey, which is summarised in Figure 2. The seismic vulnerability assessment will be carried out utilising the score assignment and the empirical approach used in the current study. As a result, vulnerability assessments of existing buildings provide information that can be used to better understand the dangers associated with structures that lack seismic design.

Analytical approaches have recently been extensively employed to create vulnerability curves. This approach incorporates a structural model Finite Element Method (FEM) study to assess existing building damage distributions. Calvi et al. [10] suggested a simple analytical vulnerability technique based on estimated building displacement and the energy dissipation capacity of the existing building. Rapid screening evaluations are appropriate for earthquake scenario projects involving a large number of structures, as investigated by Ghafar et al. [11], Mansor et al. [12], and Mohamad et al. [13]. In comparison to analytical methods such as extensive analysis procedures, which require even more time and resources and can only be employed for the evaluation of a few structures, as demonstrated by Adnan et. al. [15], Ismail et. al. [16] and Mansor et al. [12].

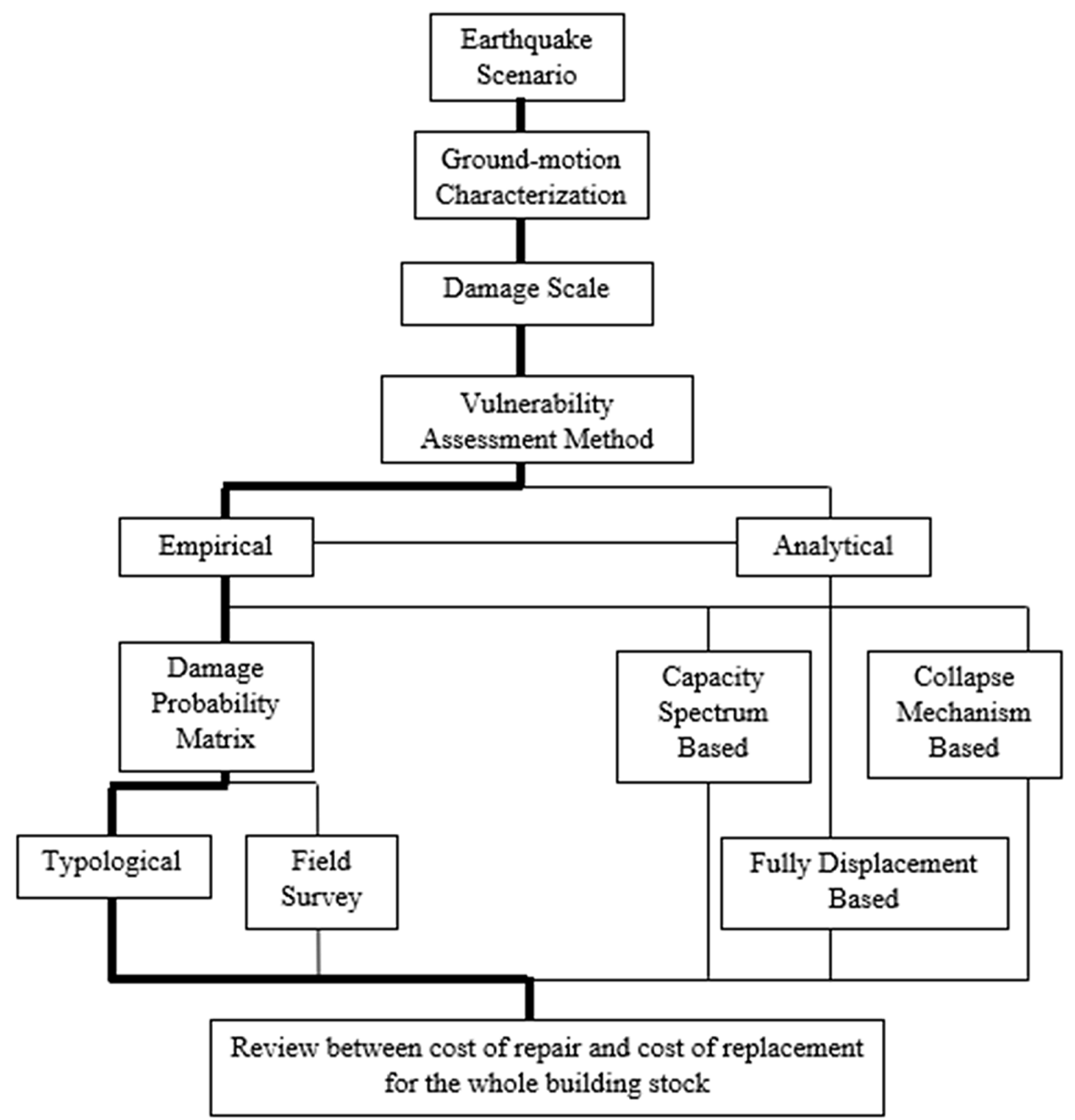

Figure 2. Typical flowchart of pushover curve method of analysis (modified from Calvi et al. [10]) 


\section{Methodology}

\subsection{Visual Screening on Existing Buildings}

Building vulnerability is a measure of how vulnerable buildings are to earthquakes. It is primarily used to assess the damage done to structures by earthquakes of varying magnitudes and to assign severity rankings to vulnerabilities. The seismic vulnerability assessment approach, which utilizes a score assignment analysis, transmits a high degree of confidence to that structure type in the event of similar future ground motions. A conventional Rapid Visual Screening (RVS) method and the FEMA 154 [14] guidebook's moderate seismicity assessment form was used to analyze 250 buildings in Kota Kinabalu city, ranging in height from low-rise to high-rise. It is a very efficient data collection method because to its low cost, quick procedure, and user-friendly guidelines. Sidewalk inspection, pre- and post-data collecting, and immediate decision-making processes are all part of the screening process. According to Mohamad et al. [17], the city of Kota Kinabalu has a total of 28,823 structures built on it. It is well known that reinforced concrete framed masonry buildings account for around $70 \%$ of the total number of buildings constructed.

In order to evaluate the need for ground motion analysis, soil information such as a soil profile is used in conjunction with other data. Because the seismic wave propagates across a large layer of bedrock and soil surface layers, which are both inelastic in nature, soil amplification is produced as a result of the earthquake. Several existing soil data sets from the city of Kota Kinabalu were used in this study to classify the soil and calculate the soil's dynamic properties. The soil dynamic properties were calculated for each data set by translating the static parameters from the standard penetration test values to equivalent soil dynamic properties [14]. Consequently, most of the land in the city is categorized as $\mathrm{C}$ and $\mathrm{D}$ soils. As seen in Table 1 , the 250 structures are spread throughout a number of different places throughout Kota Kinabalu, with the soil types in each area labelled.
Table 1. A list of the number of buildings in Kota Kinabalu in various areas, along with their respective soil type

\begin{tabular}{|c|c|c|c|}
\hline No. & District & Number of Buildings & Soil Type \\
\hline 1 & North KK 1 & 26 & C \\
\hline 2 & North KK 2 & 46 & D \\
\hline 3 & Center 1 & 93 & D \\
\hline 4 & Center 2 & 13 & C \\
\hline 5 & North East KK & 36 & D \\
\hline 6 & South KK 1 & 23 & D \\
\hline 7 & South KK 2 & 13 & D \\
\hline & Total & 250 & \\
\hline
\end{tabular}

*KK: Kota Kinabalu

The RVS evaluation technique begins with a sidewalk survey, which identifies building information such as the year of construction, soil type, number of floors, and building occupancy. Then, on top of seismic resistance criteria, any building characteristics that could have influenced seismic performance were visually scrutinised and determined. The Moderate Seismicity level of the FEMA 154 [14] evaluation form is used since Sabah is considered a zone with moderate earthquakes. Figure 3 depicts an example of an RVS data collection form filled out by a surveyor. The red dotted lines indicate where the same Basic Score Modifier is changed during the screening process.

Before the final structural score, Score Modifiers are applied to the building features, and SL1 is obtained. When a building is subjected to ground motion, the final score shows the likelihood of it collapsing. The building is classified as safe if the sum is greater than the minimum score, $\mathrm{S}_{\mathrm{MIN}}$. If the building does not score higher than the cut-off figure, it will be categorized as a dangerous structure.

The performance of existing reinforced concrete structures in the area is evaluated in the second phase of the study, which is the final section. The current study included the use of nonlinear static analysis to seven different building cases for further investigation. Demand and capacity are the two most important factors in this nonlinear static analysis process. The two curves are required in response to spectral ordinates to assess the performance of structures. 


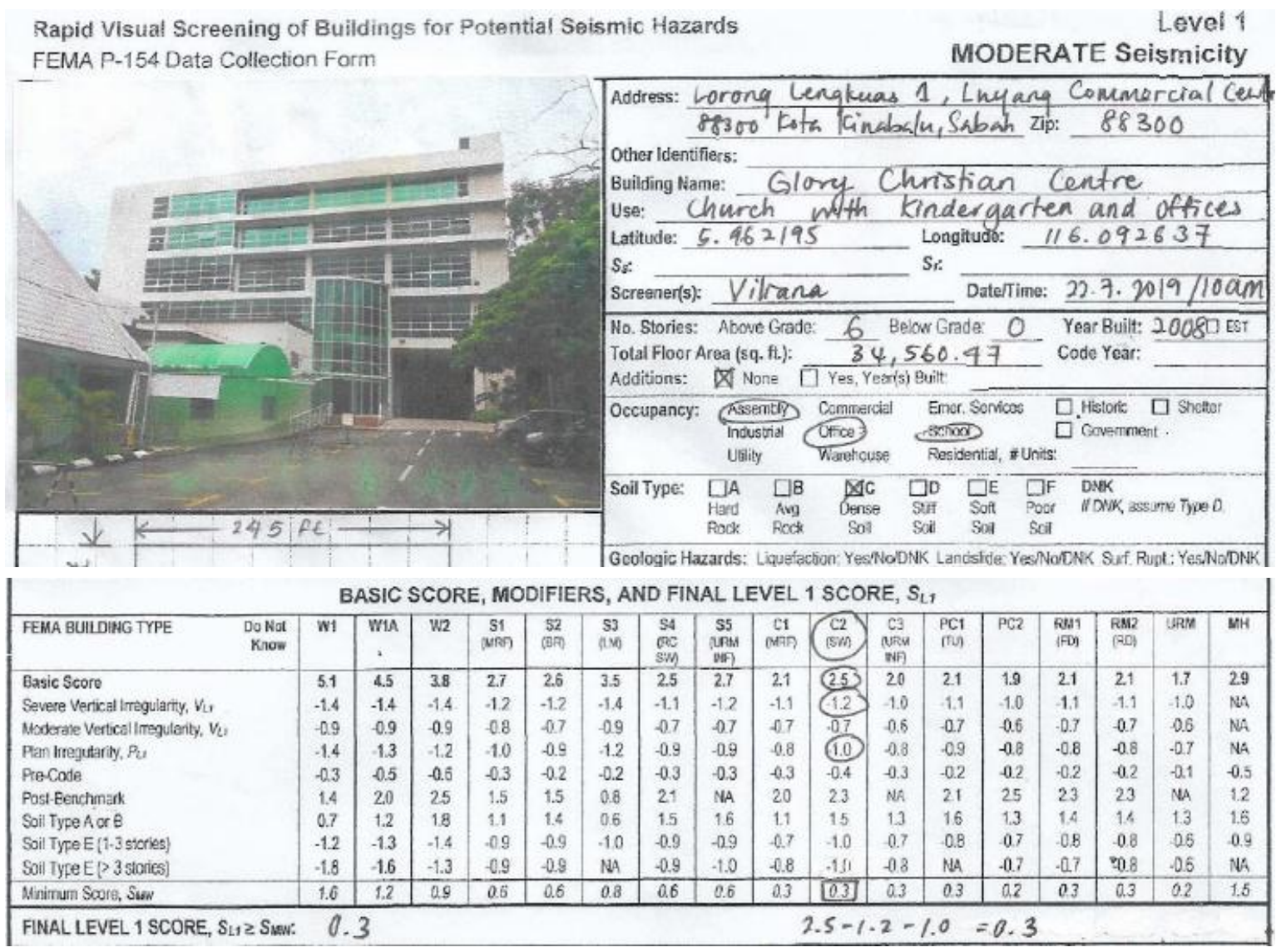

Figure 3. Example of filled out RVS Data Collection Form

\subsection{Capacity Spectrum}

Existing structures in Sabah are said to be able to resist an intensity of $0.15 \mathrm{~g}$, which is regarded to be a moderate damage level [16]. It is considered that high-rise buildings in the city of Kota Kinabalu with a total height of more than 30 stories may be susceptible to earthquake dynamic responses. Thus, an analytical seismic vulnerability assessment framework was used to seven Kota Kinabalu buildings. B1, B2, B3, B4, B5, B6 and B7 will be the names of the seven structures. Each building was subjected to a nonlinear static analysis to determine its structural performance and behaviour under the area's highest predicted ground motion intensity of $0.17 \mathrm{~g}$. The analysis allows for the application of gravity and lateral load scenarios in a single study. The main goal of this study is to provide better, more straightforward analysis processes based on capacity and demand diagrams. Through a series of applied incremental loads, the load-displacement curve could establish a structure's capacity in the inelastic condition. The capacity curve is determined by the Pushover analysis. On the $\mathrm{N}_{\mathrm{th}}$ floor, Figure 4 depicts the relationship between base shear, $V_{b}$, and roof displacement, $\mathrm{U}_{\mathrm{N}}$.

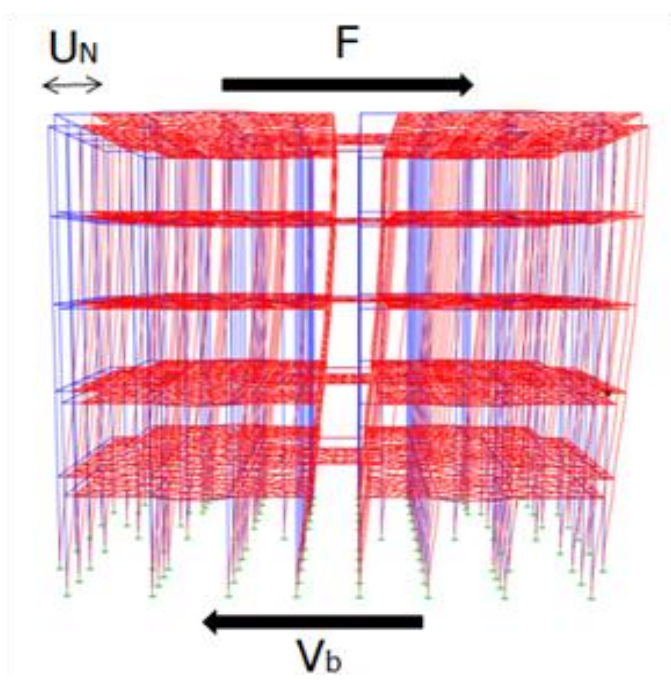

Figure 4. Building displacement under seismic loading 


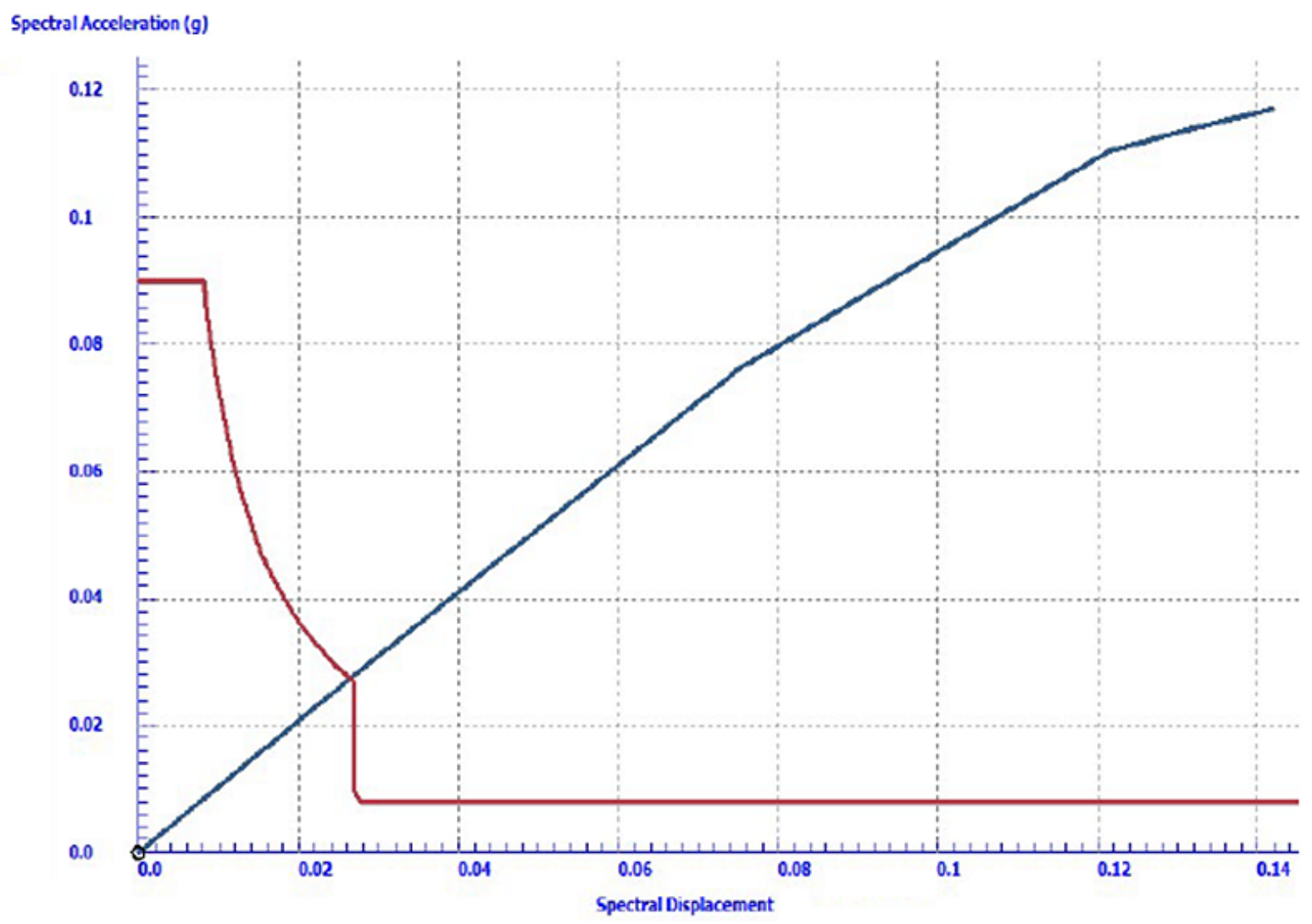

Figure 5. Capacity spectrum curve

Equations 1 and 2 below [19] are used to convert the Pushover curve into the spectral coordinates' capacity spectrum.

$$
\begin{aligned}
& S A=\frac{\mathrm{f}_{\mathrm{bs}}}{m *_{1}} \\
& S A=\frac{\mathrm{U}_{\mathrm{N}}}{r_{1} \Phi_{N 1}}
\end{aligned}
$$

Where, $b_{s}=$ base shear force, $\mathrm{U}_{\mathrm{N}}=$ displacement at $\mathrm{N}_{\text {th }}$ floor, $\mathrm{m} *_{1}=$ effective modal mass, $\Gamma_{1}=$ participation factor, $\emptyset_{1}=$ fundamental mode. The capacity spectrum curve has been converted in Figure 5 .

\subsection{Performance Point (PP)}

The performance point (PP) on the capacity curve is the point on the curve where actual displacement equals estimated target displacement. The point at which the demand and capacity spectrum curves intersect represents the building's actual displacement demand. Figure 6 depicts the individual performance level of the building as determined by pushover analysis.

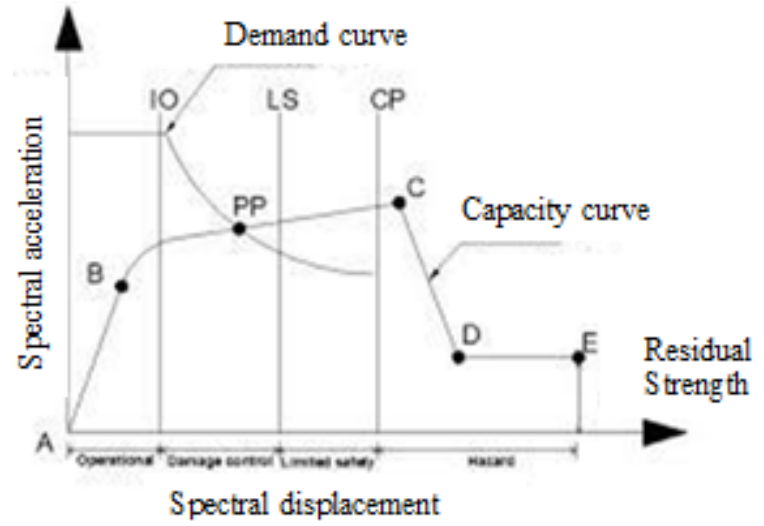

Figure 6. Elastic response spectrum plot

The building is projected to maintain no drift at the Immediate occupancy level (IO), allowing the structure to retain its initial strength and rigidity. Few residual stiffness and strength are detected at the Life safety level (LS). Furthermore, there are minimal structural drifts, and the gravity load-bearing elements are still in use. The collapse prevention level (CP) shows that the building still has some residual stiffness and strength, with load-bearing structural parts still working. At this stage, the building is projected to have more major permanent drifts and multiple extensive structural element failures. 


\section{Results and Discussion}

\subsection{Buildings Screened by RVS}

Table 2 summarizes descriptions of each of the building materials discovered in this investigation, categorizing them according to the FEMA 154 [14]. Figure 7 depicts a summary of all 250 building types in Kota Kinabalu. As a result, type $\mathrm{C} 1$ dominates $64 \%$ of the buildings. $\mathrm{C} 2$ accounts for $8 \%$ of the total. Type $\mathrm{C} 3$ buildings account for $20 \%$ of all buildings, whereas PC2 buildings account for $4 \%$. In Kota Kinabalu, there are only two types of steel materials: $2 \% \mathrm{~S} 1$ and $2 \% \mathrm{~S} 4$.

Table 2. Building Types as defined by FEMA 154 [14]

\begin{tabular}{|c|c|l|}
\hline $\begin{array}{c}\text { Building } \\
\text { material }\end{array}$ & Symbol & \multicolumn{1}{|c|}{ Description } \\
\hline \multirow{2}{*}{ Concrete } & $\mathrm{C} 1$ & $\begin{array}{l}\text { Frame structures made of concrete that resist } \\
\text { moment loads }\end{array}$ \\
\cline { 2 - 3 } & $\mathrm{C} 2$ & Buildings with concrete shear walls \\
\cline { 2 - 3 } & $\mathrm{C} 3$ & $\begin{array}{l}\text { Buildings constructed of concrete frame } \\
\text { with unreinforced masonry infill walls }\end{array}$ \\
\hline Pre-cast & $\mathrm{PC} 2$ & Buildings made of precast concrete frame \\
\hline \multirow{2}{*}{ Steel } & $\mathrm{S} 1$ & $\begin{array}{l}\text { Buildings with a steel moment-resisting } \\
\text { frame }\end{array}$ \\
\cline { 2 - 3 } & $\mathrm{S} 4$ & $\begin{array}{l}\text { Steel-framed structures with shear walls of } \\
\text { concrete }\end{array}$ \\
\hline
\end{tabular}

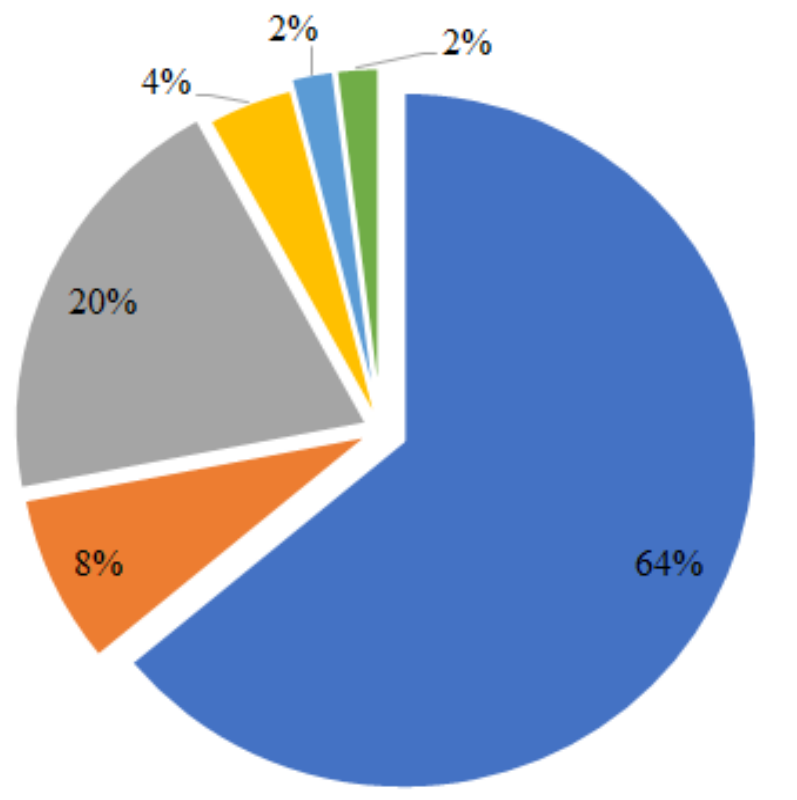

$$
\text { - } 1=\mathrm{C} 2=\mathrm{C} 3=\mathrm{PC} 2=\mathrm{S} 1=\mathrm{S} 4
$$

Figure 7. Summarization of building types in the Kota Kinabalu city

Building status is depicted in Figure 8 as either hazardous or non-hazardous, depending on the height of the building being considered (low-rise, middle-rise and high-rise buildings). According to the FEMA 154 [14] standard, the case structures are classified as seismically hazardous since their scores fall below the allowable value, whereas non-hazardous buildings have scores that are higher than the permitted value. Buildings classified as hazardous are susceptible and vulnerable to seismic hazard, while non-hazardous buildings are less vulnerable. This study collected data from around $38 \%$ of high-rise buildings, $36 \%$ of middle-rise buildings, and $26 \%$ of low-rise buildings. As a result, $24 \%$ of all high-rise buildings are classified as hazardous, whereas $14 \%$ are classified as non-hazardous. The hazardous portion of a middle-rise building is $19 \%$, whereas the non-hazardous portion is $17 \%$. Meanwhile, for low-rise buildings, hazardous and non-hazardous are given by $17 \%$ and $9 \%$, respectively.

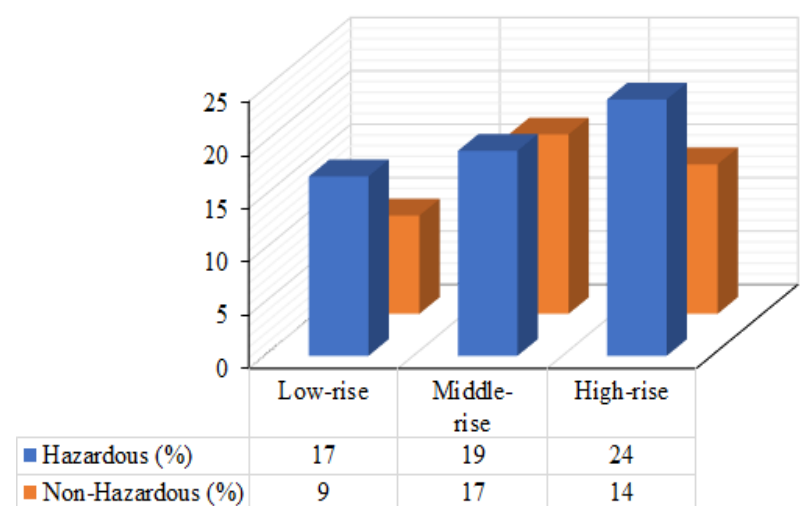

Figure 8. Building Attributes and Status on Potential Seismic Hazards

The investigation revealed that the majority of structures in Kota Kinabalu, or $60 \%$, scored below the permissible level, and were thus designated as seismically risk structures. If a major earthquake occurs, these structures are predicted to sustain significant damage or even collapse. A more thorough structural evaluation of the buildings should be carried out in this situation.

Structures, which are deemed to be at risk of collapsing as a result of seismic activity share a number of characteristics, including several severe vertical and plan irregularities in their structural components. According to the data on plan irregularities and vertical irregularities, vertical irregularities can be found in $91 \%$ of the building stock, while plan irregularities can be found in $71 \%$ of the building stock across all types of structures. Seventy percent of the buildings in the database have structural features that are irregular in both their plan and vertical orientation. Thus, according to the RVS building evaluation analysis statistics, the majority of hazardous buildings will sustain structural damage ranging from Grade 3 to Grade 4 according to the FEMA 154 [14] standard, which in result of a high probability.

\subsection{Building Performance Level}

Seven reinforced concrete buildings were subjected to an analytical seismic vulnerability assessment framework. Figure 9 depicts the floor layout for the building. 


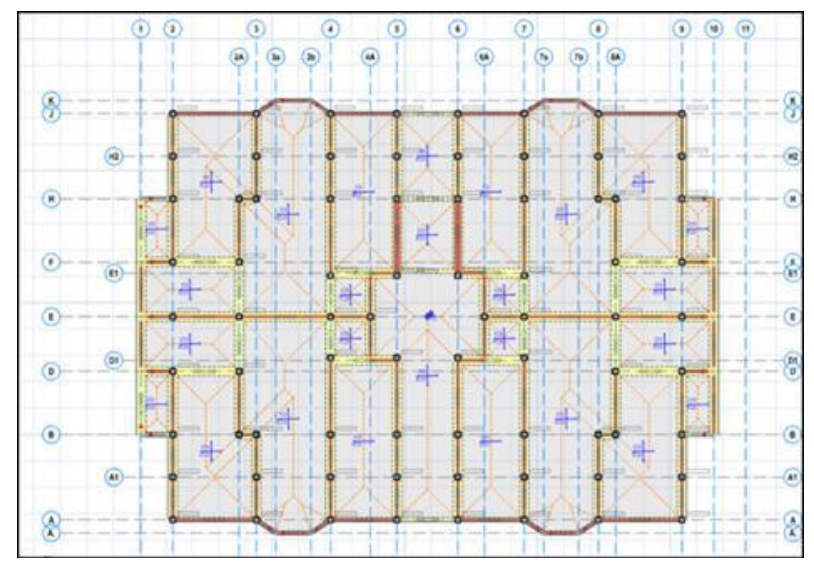

Figure 10. An example of a building plan for a Kota Kinabalu structure

Pushover study was carried out on seven structural models that were subjected in both the $\mathrm{X}$ and $\mathrm{Y}$ directions, respectively. Because they were examined in this manner, each structure has a specific performance level and points. Tabulated in Table 3 is the performance point (base shear, $\mathrm{V}$ in relation to top displacement, D). Table 4 provides the Spectral Displacement (Sd) and Spectral Acceleration (Sa). The structural response of a building when subjected to earthquake stresses is depicted in Figure 10.

Table 4. Performance points

\begin{tabular}{|c|c|c|}
\hline \multirow{2}{*}{ Buildings } & \multicolumn{2}{|c|}{ Performance Point } \\
\hline & $\mathbf{V}(\mathbf{m} / \mathbf{s})$ & $\mathbf{D}(\mathbf{m})$ \\
\hline $\mathrm{B} 1$ & 2594 & 0.038 \\
\hline $\mathrm{B} 2$ & 564 & 0.028 \\
\hline B3 & 21807 & 0.078 \\
\hline B4 & 5249 & 0.025 \\
\hline B5 & 2908 & 0.009 \\
\hline B6 & 10491 & 0.005 \\
\hline B7 & 310 & 0.004 \\
\hline
\end{tabular}

Table 5. Performance points in Acceleration-Displacement Response Spectrum

\begin{tabular}{|c|c|c|}
\hline \multirow{2}{*}{ Building Tag } & \multicolumn{2}{|c|}{ Performance Point } \\
\cline { 2 - 3 } & $\mathbf{S}_{\mathbf{d}}(\mathbf{m})$ & $\mathbf{S}_{\mathbf{a}}\left(\mathbf{m} / \mathbf{s}^{\mathbf{2}}\right)$ \\
\hline B1 & 0.026 & 0.027 \\
\hline B2 & 0.022 & 0.059 \\
\hline B3 & 0.014 & 0.052 \\
\hline B4 & 0.012 & 0.010 \\
\hline B5 & 0.011 & 0.033 \\
\hline B6 & 0.002 & 0.048 \\
\hline B7 & 0.003 & 0.046 \\
\hline
\end{tabular}

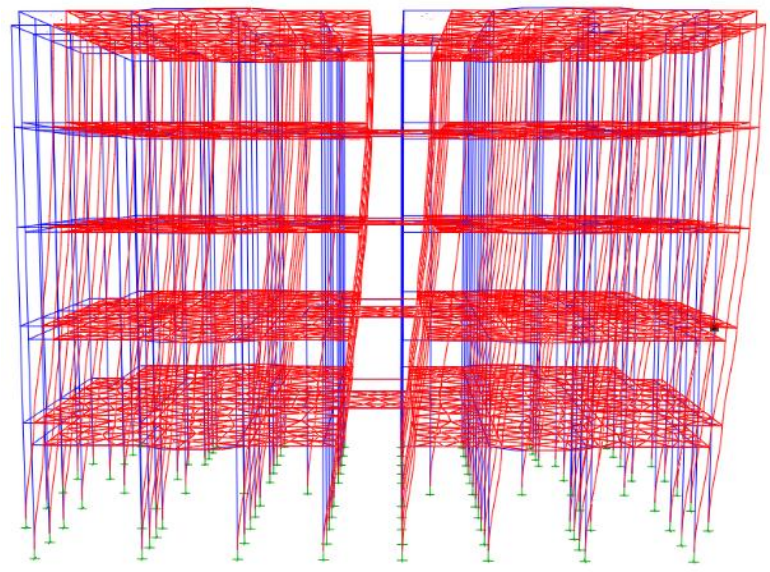

Figure 11. Building displacement along the $\mathrm{X}$ direction

Construction of buildings B1, B2, B3, and B5 revealed that their performance points were in the elastic zone as defined by the MS EN 1998 [18] response spectrum. The early part of the analysis, based on the Pushover graphs, yields a linear slope from the origin, which represents the overall structure stiffness in their elastic range during the early stage of the analysis. As more hinges are added to the framework, the overall rigidity of the structure begins to deteriorate. It is shown by the drop in the first slope line of the pushover curve that there has been a change in structural stiffness. While the time, $\mathrm{T}$, is increasing and the time is being moved from $T_{a}$ to $T_{b}$, the increase in damping ratio, is also increasing, which means that the Response Spectrum curve is lowering.

As seen in Figure 11, many hinges are produced during the last steps of the nonlinear analysis. The importance of the lateral push in producing more vital reactions is extensively considered. The colour code for hinge statuses is green when the building is ready for immediate occupancy (IO), orange when the building is ready for life safety (LS), and red when the building is ready for collapse prevention (CP). The number of hinges in the model constructions appears to differ, despite the fact that they all performed at a similar level of Life Safety (LS). The results show that the majority of hinge formations are found within the LS-CP states in the Performance Point at the top. According to the Pushover results, the members of beams and columns with the most severely yielded hinges are those with the most severe yielding. As the analysis progresses, the weakening of hinges causes a continual change in the equivalent damping ratio, and the time, $\mathrm{T}$, as seen in the graph. 


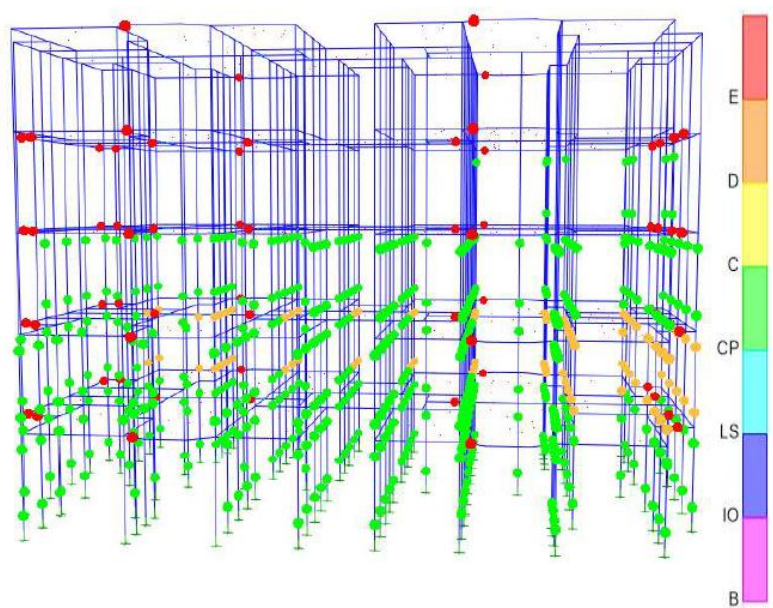

Figure 12. Hinges formation on building

\section{Conclusions}

Results of Rapid Visual Screening (RVS) building evaluations reveal that 60 percent of the case buildings are hazardous and pose a high risk when subjected to a moderate earthquake, according to the report. High-rise buildings account for $24 \%$ of the total, middle-rise buildings account for 19\%, and low-rise structures account for $17 \%$. Grade 3 to Grade 4 structural damage is a distinct possibility in this situation. Buildings that received a score lower than the benchmark value in the FEMA [14] scoring form or $\mathrm{S}$ value is less 2.0 indicate that a deeper examination is unavoidable for further evaluation of the building. According to the results of the Nonlinear Static analysis, more than half of the building stock exhibits a linearly elastic response when subjected to the design peak ground acceleration (PGA) level (0.17 g). It was predicted that structures built before the seismic code would suffer early damage accumulation. As a result of the subjectivity of essential data and modelling concerns in the analytical risk assessment, there are ambiguities and inaccuracies in determining the actual seismic response of the buildings under consideration. When assessing the vulnerability of a structure in the future, appropriate approaches and procedures should be performed in order to determine the most appropriate retrofitting method.

\section{Acknowledgments}

It is with great respect that we convey our gratitude for the financial assistance provided by SDN0041-201 and GUG0302-2/2018. We'd like to offer our heartfelt appreciation to the anonymous reviewers for their astute observations.

\section{REFERENCES}

[1] W. J. F. Simons, A. Socquet, C. Vigny, B. A. C. Ambrosius, S. Haji Abu, C. Promthong, W. Spakman. A decade of GPS in Southeast Asia: Resolving Sundaland motion and boundaries. Journal of Geophysical Research: Solid Earth, Vol.112, B06420, 1-20.

[2] H. D. Tjia. Kundasang (Sabah) at the intersection of regional fault zones of Quaternary age. Geological Society of Malaysia Bulletin, Vol.53, 59-66, 2007

[3] Y. Alexander, A. Liau, M. Hamzah, M. Y. Ramli, M. B. Mat Taib, A. Ali, H, Ariffin, B. Ismail, H. D. Tjia. Seismic and Tsunami Hazards and Risks Study in Malaysia. Assessment of the Seismic Threats to Malaysia from Major Earthquake in the Southeast Asian Region. Ministry of Natural Resources and Environment, Kuala Lumpur, 2008.

[4] C. H. Leyu. Seismic and Tsunami Hazards and Risks Study in Malaysia. Summary for Policy Makers, 2009.

[5] M. Azhari. Monitoring Active Faults in Ranau, Sabah Using GPS.19th United Nations Regional Cartographic Conference for Asia and the Pacific, Bangkok, 2012.

[6] Z. A. Mohd Hazreek, R. S., Fauziah Ahmad, D. C. Wijeyesekera, M. F. Tajul Baharuddin. Seismic Refraction Investigation on Near Surface Landslides at the Kundasang area in Sabah, Malaysia. Procedia Engineering, Vol.50, 516- 531.

[7] G. E. Wilford. Earth tremors in Sabah. Sabah Society Journal, Vol.3, 136-138.

[8] K. Inus. More earthquakes expected for Sabah in near future: UMS. Online available from https://www.nst.com.my/news/nation/2017/09/275495/mor e-earthquakes-expected-sabah-near-future-ums.

[9] K. Lang. Seismic Vulnerability of Existing Buildings, IBK Report No. 273, Swiss Federal Institute of Technology (ETH), Zurich, Switzerland, 2002.

[10] G. M. Calvi, R. Pinho, G. Magenes, J. J. Bommer, L. F. Restrepo-Vélez, H. Crowley. Development of Seismic Vulnerability Assessment Methodologies over the Past 30 Years. ISET Journal of Earthquake Technology, Vol. 43, 75-104.

[11] M. Ghafar, N. Ramly, M. Alel, A. Adnan, E. T. Mohamad, M. Z. M. Yunus. A Simplified Method for Preliminary Seismic Vulnerability Assessment of Existing Building in Kundasang, Sabah, Malaysia. Jurnal Teknologi, Vol. 72, No. 3, 1-7.

[12] M. N. A. Mansor, L. C. Siang, A. Ahwang, M. A. Saadun, J. Dumatin. Vulnerability Study of Existing Buildings Due to Seismic Activities in Sabah. International Journal of Civil Engineering \& Geo-Environmental, 137-147.

[13] I. I. Mohamad, M. Z. M. Yunus, N. S. H. Harith, P. Lestuzzi. Vulnerability Assessment of Buildings in Ranau Township: Methodological Design. Jurnal Kejuruteraan, Vol.2, No.1, $1-7$.

[14] FEMA 154. Rapid Visual Screening of Building for Potential Seismic Hazards. A Handbook, Redwood City, CA, 2002 
[15] A. Adnan, S. Suradi, P. N. Selvanayagam, Z. Darus. Vulnerability of Public Buildings Subjected to Earthquake by Finite Element Modelling. Proceedings of the 6th Asia-Pacific Structural Engineering and Construction Conference, 259-269, 2006

[16] R. Ismail, A. Adnan, A. Ibrahim. Vulnerability of Public Buildings in Sabah Subjected to Earthquake by Finite Element Modelling. Procedia Engineering, Vol. 20, 54-60.

[17] Z. Mohamad, Z. Ramli, M. Zulkarnain A. Rahman, M. R. M. Salleh, Z. Ismail, M. F. A. Khanan. Vulnerability Mapping and Analysis: An Implementation in Geohazard Areas in
Sabah. The International Archives of the Photogrammetry, Remote Sensing and Spatial Information Sciences, Kuala Lumpur, Malaysia, 189-200, 2018.

[18] MS EN 1998-1:2015. Malaysia National Annex to Eurocode 8: Design of structures for earthquake resistance Part 1: General rules, seismic actions and rules for buildings. (National Annex:2017). Department of Standards Malaysia, 2017.

[19] ATC-40. Seismic evaluation and retrofit of concrete buildings. Applied Technology Council, Redwood City, California, 1996. 